\title{
A MATERIALIDADE DO TRABALHO EM TERRITÓRIOS DAS ÁGUAS, TERRAS E FLORESTAS DA AMAZÔNIA ${ }^{1}$
}

\author{
Arminda Rachel Botelho Mourão² \\ Iraci Carvalho Uchôa ${ }^{3}$ \\ Heloísa da Silva Borges ${ }^{4}$
}

\begin{abstract}
Resumo
O artigo analisa a materialidade do trabalho e a sua organização na comunidade de Nogueira/Alvarães/Amazonas, apresentando um panorama das relações de trabalho na Amazônia. Os procedimentos metodológicos foram estudos bibliográficos e de campo, tendo o materialismo histórico dialético como método para apreciação e análise dos dados. Conclui-se que no campo das terras, águas e florestas, a força de trabalho relaciona-se aos ciclos da natureza e que, frente à ausência/insuficiência de políticas públicas de Estado, cabe aos/as trabalhadores/as enfrentar diversos desafios.
\end{abstract}

Palavras-chave: Trabalho no campo; Trabalhadores amazônidas; Educação do Campo.

\section{LA MATERIALIDAD DEL TRABAJO EN LOS TERRITORIOS DEL AGUA, TIERRAS Y FLORESTAS DE LA AMAZONIA}

\section{Resumen}

El artículo analiza la materialidad del trabajo y su organización en la comunidad de Nogueira/Alvarães/Amazonas, presentando una visión general de las relaciones de trabajo en la Amazonía. La metodología se basó en estudios bibliográficos y de campo, adoptando el materialismohistórico dialéctico como método para la apreciación y el análisis de los datos. Se concluye que en el campo de las tierras, aguas y florestas, la fuerza de trabajo se relaciona con los ciclos de la naturaleza y que, delante de la ausencia/insuficiencia de políticas públicas estatales, tocan a los trabajadores/as enfrentar muchos desafíos.

Palabras chave: Trabajo en el campo; Trabajadores amazónicos; Educación del campo

\section{MATERIALITY OF LABOR IN AMAZONIAN WATER, LAND AND FOREST TERRITORIES}

The article analyzes the materiality of the work and its organization in the community of Nogueira/Alvarães/Amazonas. With a view to this, it provides an overview of working relations in Amazon. The methodology was based on bibliographic and field studies, adopting the dialectical materialismhistorical method for data appreciation. It is concluded that: The workforce in the community field is related to nature cycles; and workers face real challenges due to the absence of state policies.

Keyword: Work in the field; Amazonian workers; Field Education.

\footnotetext{
${ }^{1}$ Artigo recebido em 29/04/2020. Primeira avaliação em 01/06/2020. Segunda avaliação em 02/06/2020. Aprovado em 16/08/2020. Publicado em 25/09/2020. DOI: https://doi.org/10.22409/tn.v18i37.46279

2 Doutora em Educação pela Pontifícia Universidade Católica de São Paulo (PUC-SP) - Brasil. Professora Titular da Universidade Federal do Amazonas (UFAM) - Brasil. E-mail:mailto:armindaufam@gmail.com ORCID: 0000-0002-1940-9477. Lattes: http://lattes.cnpq.br/3864748731992379

${ }^{3}$ Doutoranda em Educação na Universidade Federal do Amazonas (UFAM) e Mestre em Educação pela Universidade Federal do Amazonas (UFAM) - Brasil. Professora da Secretaria Municipal de Educação SEMED (Padre Pedro Vignola) - Amazonas / Brasil. E-mail:mailto:irauchoa100@outlook.com ORCID: 0000/0003-1794-924X. Lattes: http://lattes.cnpq.br/0565932748535945

${ }^{4}$ Doutorado em Educação e Mestrado em Educação pela Universidade Federal do Amazonas (UFAM) Brasil. Atualmente Professora do Departamento de Administração e Planejamento e do Programa de PósGraduação em Educação, da Faculdade de Educação, da Universidade Federal Amazonas - Brasil. E-mail: helo-borges@hotmail.com ORCID: 0000-0001-7629-7056 Lattes: http://lattes.cnpq.br/9429409939324333
} 


\section{Introdução}

O artigo é o resultado de uma pesquisa inserida no eixo de políticas públicas educacionais, com lócus no município de Alvarães/Amazonas ${ }^{5}$. Os sujeitos foram os/as trabalhadores/as da comunidade e professores/as das escolas de classes multisseriadas que participaram do Programa Escola da Terra6 ${ }^{6}$. Salienta-se que suas identidades foram preservadas, conforme orientação do Comitê de Ética ${ }^{7}$.

Durante a realização das atividades de formação continuada dos professores/as das escolas do campo do referido município, questões referentes à forma de vida nesse território foram socializadas, tais como: a) cultura; b) história; c) acesso e permanência na escola; d) organização e materialização do trabalho. Dentre esses temas debatidos, o último nos aguçou analisá-lo, pois em territórios de águas, terras e florestas compreendemos que o trabalho é a categoria fundante, pois o homem ao modificar a natureza modifica-se, transformando seu ambiente e constrói sua cultura, garantindo a existência na comunidade de Nogueira.

Nesse sentido, formulamos a seguinte problemática: Como se materializa o trabalho e sua organização na comunidade de Nogueira/ Alvarães/Amazonas? Diante do problema levantado foi elaborado o projeto de pesquisa, que proporcionou a realização do estudo, tendo como objetivo: Analisar materialidade do trabalho e a sua organização em territórios de águas, terras e florestas no contexto amazônico.

Para Witkoski (2010, p. 169):

O trabalho e os produtos do trabalho da unidade de produção só são possíveis porque a família funciona como uma espécie de "máquina humana produtiva", onde todos devem e não podem deixar de participar da vida produtiva; seja fundamentalmente para subsistência [...] ou comercialização de eventuais excedentes, todos os membros da família devem trabalhar [...].

No território da comunidade de Nogueira essa existência significa que os

\footnotetext{
5. O Estado o Amazonas tem 62 (sessenta e dois) municípios, o Programa Escola da Terra atendeu 46 (quarenta e seis), desenvolvendo também a especialização. Deste trabalho se originaram várias pesquisas, esta refere-se a uma delas.

${ }^{6}$ Em desdobramento a Portaria no 679 de julho, foi instituído o Programa Escola da Terra como uma das ações do Programa Nacional da Educação do Campo - PRONACAMPO, no qual compõe o primeiro eixo articulador que trata das categorias: Gestão e Práticas Pedagógicas.

${ }^{7} \mathrm{~A}$ pesquisa tem autorização do Comitê de Ética e, portanto, os pesquisados assinaram o Termo de Consentimento Livre Esclarecido, que na tentativa de preservar suas identidades foram utilizados nomes de rios para identificar os sujeitos concretos, protagonistas de suas histórias.
} 
produtos agrícolas cultivados são para além do consumo doméstico. Esse processo se dá em razão de que há produtos que os/as trabalhadores/as não cultivam, e para obtê-los precisam comprá-los. A terra, a floresta e a água participam de modo decisivo da forma como esses/as trabalhadores/as procuram dar plenitude à vida. "A terra e as riquezas que ela guarda são valorizadas como um patrimônio que cria as condições para que os/as trabalhadores/as apareçam como protagonistas de sua unidade de produção" (WITKOSKI, 2010, p. 191).

A pesquisa permitiu a compreensão que o trabalho desenvolvido na terra pelo/a trabalhador/a na agricultura familiar é para a produção de mandioca, melancia, milho e hortaliças em geral. Essa produção é para o uso doméstico e para a comercialização, entretanto, parte do produto destinado à venda fica à deriva, em função de não haver transporte para a sua comercialização na cidade. Esse movimento acentua o direito de ações efetivas de políticas de escoamentos para a produção. Segundo Marx (1982, p.94) "não é com os pés que as mercadorias vão aos mercados, nem se trocam por decisão própria". Nesse sentido, os/as trabalhadores/as devem levar suas produções agrícolas ao mercado, implicando relações mútuas entre capital e trabalho. Essa relação de troca demonstra-se como um processo individual, contudo, não se desvincula de um processo social, conforme Marx (2011, p.864) "usar é consumir, seja para a produção, seja para o consumo. Trocar é esse ato mediador por um processo social. Ou seja, o próprio uso pode ser posto pela troca e ser mera consequência dela".

No âmbito dessas relações, os/as trabalhadores/as da comunidade de Nogueira precisam de transporte fluvial para comercializar os produtos cultivados. Esse transporte fluvial é, portanto, resultado de uma política pública que emerge a partir da realidade concreta e da materialidade do trabalho em territórios de águas, terras e florestas no contexto amazônico.

A ausência de políticas públicas nesses territórios é o reflexo da correlação de força entre capital e trabalho. A implicação dessa correlação de força resulta em produtos à deriva nas margens dos rios, como por exemplo, a melancia e o milho, dentre outros que ficam à espera de um transporte que garanta o seu deslocamento aos estabelecimentos de vendas. É importante considerar que o território amazônico garante a existência de pessoas, de vidas, de saberes, de tradições, de culturas, de gestos e de costumes e por essas razões, a não implementação de 
políticas públicas efetivas caracterizam o negligenciamento de uma classe historicamente excluída de seus direitos.

O território amazônico é constituído pelas águas, terras e florestas, que são territórios de trabalho. "O território é um produto das ações coletivas, uma construção histórica do homem à medida que esse se organiza culturalmente" (PEREIRA, et al, p. 215, 2009). Nesse território as relações sociais se construíram historicamente no trato do ser - humano com a natureza. (WITKOSKI,2010), existindo várias comunidades amazônicas com diversidades culturais que atravessaram gerações e que se consolidaram no processo histórico.

O artigo está dividido em três partes. A primeira seção é a contextualização da comunidade de Nogueira. A segunda seção se insere na categoria central, que é o Trabalho; e se desdobram discussões sobre a agricultura familiar camponesa apontando que no campo, a comunidade é a unidade de produção do trabalhador e trabalhadora de uma região do Médio Rio Solimões/AM. A terceira seção aborda a organização do trabalho e por fim, as considerações finais.

\section{Contextualização da comunidade de Nogueira}

As águas negras, a floresta, a areia, os igarapés, as terras de várzeas e terras firmes, a cheia, a seca são aspectos particulares que caracterizam Nogueira, na região de Alvarães (UCHOA \& MOURÃO, 2019). A comunidade é para os trabalhadores/as um território em que as relações se constituem, "os aspectos culturais, as tradições se interligam, a economia, a religião, a política, diversos aspectos de uma cultura aparecem interligados e formam parte de um sistema geral de cultura, tais como o são na realidade" (WAGLEY, 1988, p. 44).

É o campo dos sujeitos que migraram de comunidades distintas e constituíram a base familiar; consolidaram laços e se relacionam com os modos e costumes que caracterizam a vida na comunidade.

Esse é um recorte da imensidão do território amazônico, local que representa a existência de um povo, que tem a terra como matriz fundamental para existir e coexistir. A comunidade de Nogueira que apresenta as possibilidades de existência de tantos, localiza-se ao norte do município de Alvarães - Rio Solimões - faz extremidade ao Sul com o Lago de Tefé, a Leste com o Igarapé do Grilo, a Oeste 
com o Igarapé do Minerva e situa-se no Centro-Oeste do Estado do Amazonas. A extensão territorial da comunidade é de aproximadamente $11.000 \mathrm{~km}$, o acesso para quem sai do Porto de Tefé é por via fluvial e de quem sai do Porto de Alvarães se faz por via terrestre ou fluvial (UCHOA \& MOURÃO, 2019).

A comunidade de Nogueira tem uma diversidade cultural que ao longo dos anos se constituiu e se reconstruiu. É uma comunidade de terra firme e terra de várzea, a seca evidencia a beleza e riqueza natural da praia, local de recreação para os sujeitos que utilizam aquele território como um dos meios de diversão que a dialética da natureza possibilita (UCHOA \& MOURÃO, 2019).

A praia é um ponto turístico, pois reúne a população de Nogueira, e de regiões como Alvarães ${ }^{8}$ e Tefé ${ }^{9}$. Aos domingos e feriados, é cenário do lazer, caracteriza-se também, por ser um local de passagem de viajantes e comerciantes que utilizam os motos-taxistas e as canoas como transporte para percorrer as terras e navegar as águas do Lago de Tefé e Rio Solimões em direção aos municípios adjacentes.

A canoa é uma das formas de transporte mais utilizada pelos trabalhadores/as da comunidade, com destino aos rios, furos ${ }^{10}$ e igapós, locais onde retiram da natureza a sua existência. Para Silva (2016, p. 30), "a canoa ou casco, é a arquibancada do tempo, cujo fundo está coberto por ramos de capim ou de folhas de árvores protegendo os peixes capturados", nela o/a trabalhador/a vai à procura da dieta alimentar da família que é totalmente orgânica. O remo é um dos instrumentos usados pelos/as trabalhadores/as que prevalece como condutor a impulsionar a canoa a navegar as águas.

Esses objetos são característicos das singularidades amazônicas, são elaborados por meio de saberes históricos. Os trabalhadores e as trabalhadoras carregam em suas costas os rabetões ${ }^{11}$ até o porto da comunidade e acoplam na

\footnotetext{
${ }^{8}$ Alvarães é um município do Estado do Amazonas, Região Norte do Brasil. Pertence à Mesorregião do Centro Amazonense e Microrregião de Tefé, localiza-se a oeste de Manaus, capital do estado. Sua população é de 16.041 habitantes, dados estimados pelo Instituto Brasileiro de Geografia e Estatística (IBGE).

9 Tefé é um município do Estado do Amazonas. Sua população, segundo estimativas do Instituto Brasileiro de Geografia e Estatística (IBGE), é de 59.842 habitantes. Sua área territorial é de 23. 808 quilômetros quadrados.

${ }^{10}$ É um termo utilizado pelos moradores das margens dos rios no Amazonas e significa um pequeno percurso que permite $o$ atalho de uma longa curva de rio.

${ }^{11} \mathrm{O}$ dicionário da Língua Portuguesa define como rabeta, um pequeno motor que acoplado à traseira de uma canoa, é conduzido manualmente com ajuda de um bastão que determina a direção.
} 
popa $^{12}$ da canoa com a finalidade de percorrer os locais em que cultivam suas produções agrícolas.

Os instrumentos de trabalho formados pela canoa e o remo são a realeza que agregam as particularidades das regiões amazônicas, visto que para Silva (2010, p.119), “o rabetão no Rio Solimões é a majestade. Ele leva e traz pessoas, vidas, saberes e narra com a dança das águas a vida daquele que vive num trânsito constante" entre o campo e a cidade; esse é o cenário territorial que permeia a calha do Médio Solimões e a comunidade de Nogueira (UCHOA \& MOURÃO, 2019).

Ao desvelar a comunidade na visão de quem avista pela primeira vez, se depara com o contraste da cultura do campo e da cidade. Existem casas de alvenaria, de madeira e mistas; as mistas são caracterizadas pelas estruturas de alvenaria e as paredes de madeira. A comunidade possui uma Associação Comunitária, uma escola da rede municipal, um posto de saúde, dois campos de futebol, uma casa de reuniões comunitárias, uma Igreja Católica fundada em meados do século XIX, duas Igrejas Protestante-Assembleia de Deus, duas ruas que - cujos nomes são Rio Niterói e Rio de Janeiro - dividem aproximadamente oitenta residências e residem aproximadamente trezentas pessoas. (UCHOA \& MOURÃO, 2019).

Destaca-se que mesmo existindo na comunidade duas Igrejas protestantes, é perceptível o respeito que os moradores apresentam pelo catolicismo, visto que comemoram no dia sete de outubro, o aniversário da padroeira: Santa Nossa Senhora do Rosário.

As casas com arquiteturas cidade - campo, como já foi mencionado, possuem televisão, rádio, geladeira e antena parabólica. As residências visitadas no decorrer da pesquisa de campo, realizada em 2016, são construídas em terrenos planos, cercadas por árvores frutíferas, existem nos quintais criações de animais, uma horta ao fundo, local que se cultivam as hortaliças e plantas medicinais, tais como capimsanto, alecrim, camomila, hortelã, anador, penicilina e cibalena. "As plantas medicinais fazem parte do cotidiano dos trabalhadores/as, que utilizam mais de 60 espécies cultivadas em canteiros residenciais" (SILVA, 2010, p.149).

Dicionário da Língua Portuguesa. Disponível em: https://www.dicio.com.br/rabeta. Acesso dia 28 de novembro de 2017.

12 Parte traseira de um meio de transporte fluvial. 
O território de Nogueira é caracterizado pelo plantio da mandioca, da macaxeira, banana, abacaxi, cará, açaí, do milho e da melancia - produtos que formam a base alimentar dos sujeitos que ali residem. As espécies são cultivadas pelos/as trabalhadores/as em função de obter produtos para a sua existência no campo. Esses sujeitos utilizam a terra, as águas e as florestas como condutoras no processo de produzir e reproduzir os usos múltiplos dos recursos naturais. Essa forma de produzir dialoga com a perspectiva da agricultura familiar que, para Caldart, Molina e Arroyo (2000, p. 42) significa "diversidade, no uso múltiplo dos recursos naturais". Entretanto, a visão que ainda prevalece na sociedade é a que considera o campo lugar do atraso, do inferior, e do arcaico. O que na verdade é uma falsa imagem, pois coloca a cidade como o único espaço de desenvolvimento, desvalorizando os processos produtivos dos que residem no campo.

A comunidade é atendida pelo Programa Luz Para Todos, direito que possibilita qualidade de vida aos moradores, facilita a conservação dos alimentos, meios de comunicação e entretenimentos. Juruá, 67 anos, agricultora da comunidade destaca: "hoje aqui na comunidade, nós temos a opção de congelar os peixes, fazemos dindinho ${ }^{13}$, e as crianças adoram, eu não perco a novela que passa todo dia, depois do almoço, estico o meu tupé ${ }^{14}$, e só levanto depois que acaba aí vou para o roçado" (CADERNO DE PESQUISA DE CAMPO, 2016).

É importante destacar que uma das particularidades da comunidade é o uso do jirau. O jirau se configura como uma área de serviço doméstico utilizada pelos trabalhadores/as de Nogueira. É ali, que os peixes são tratados, se armazenam água, ocorrem as higienizações dos utensílios, é o local do majestoso fogão à lenha, traços dos povos tradicionais que residem na região desde o período da colonização do Amazonas (UCHOA \& MOURÃO, 2019).

$\mathrm{Na}$ Comunidade de Nogueira, a Associação Comunitária é formada pelo Presidente, Vice-Presidente, Secretário e Tesoureiro, coletivamente reivindicam para a melhoria da qualidade de vida dos que nela reside, uma das reivindicações se relaciona às políticas públicas, como por exemplo, escoamento das produções que é inexistente. Fazem isto, por meio de reuniões, e encaminham seus anseios à prefeitura do município. O que também reivindicam é a valorização e o registro dos

\footnotetext{
${ }^{13} \mathrm{Em}$ outras regiões do país é conhecido como sacolé.

${ }^{14}$ É um instrumento de origem chão indígena utilizado para forrar o.
} 
produtos destinados à comercialização. Lutam pelo registro dos produtos cultivados, para que o consumidor tenha o conhecimento de sua origem como 0 local, a data e o nome de quem produziu. (UCHOA \& MOURÃO, 2019).

Segundo Caldart e Kolling (2002, p. 10), "a participação em uma organização coletiva cria traços fundamentais no perfil do ser humano que precisamos formar na atualidade: lutadores e construtores". Os/as trabalhadores/as de Nogueira se organizam em função de reivindicar melhores condições de vida no campo, e deste modo potencializam a cultura e os processos produtivos locais.

Esses movimentos são em razão de que o sujeito percebe que a forma como são comercializados seus produtos, bem como, ausência de registro, acabam por desvalorizar sua produção agrícola. Ao reconhecer essa negação, ocorre um movimento que os possibilitam se reconhecerem como sujeitos de direitos, e decorrentes das lutas, surgem políticas públicas ancoradas à realidade do trabalho, que se contrapõe a figura do atravessador, já que esse é um dos autores coadjuvantes do modo de produção capitalista presente no campo. (UCHOA \& MOURÃO, 2019).

$\mathrm{Na}$ comunidade, existem famílias antigas que se constitui no grupo de trabalhadores/as mais antigos; esses se conheceram e estreitaram laços de parentesco que passaram de geração a geração. Os vínculos refletem nos modos de organização do trabalho. É típico o casamento entre primos; esses residem no mesmo teto que os pais e assim estabelecem as bases familiares. Esse fato se torna relevante no processo de produção, isto porque, conseguem transformar uma quantidade maior de "bens in natura, em produtos, resultados da ação coletiva coordenada da unidade familiar, o que acaba contribuindo, de maneira significativa, para a subsistência da unidade familiar" (WITKOSKI, 2010, p. 164).

Os sujeitos da pesquisa se reconhecem como indígena, negro ou pardo, é trabalhador, é católico ou protestante, uns são analfabetos, outros concluíram a Educação Básica, outros o Ensino Superior. Entretanto, todos possuem conhecimentos amplos no que se refere aos saberes tradicionais, passados de geração a geração, mesmo com o advento da tecnologia, que sim, chega ao campo. São trabalhadores/as que se caracterizam como sujeitos que, ao longo do processo histórico construíram laços permanentes com a natureza e, no compasso do trabalho na terra com a agricultura, produzem sua existência. 


\section{O Trabalho na terra/floresta/água e sua organização no campo da comunidade}

Ao discutir o Trabalho na terra, especificamente na Agricultura Familiar, é fundamental retomar o entendimento de que no Brasil, existem dois campos; o primeiro é o da Educação do Campo, que nas perspectivas de Oliveira (2007) e Molina (2003), não é adepto ao produtivismo e caracteriza-se pelo uso múltiplo do solo. O segundo, é o campo do Agronegócio capitaneado pela classe dominante, cujo objetivo é a concentração e expansão econômica (MOURÃO, 2012).

O recorte pesquisado converge com a Agricultura Familiar Camponesa. É na comunidade de Nogueira que as múltiplas culturas são cultivadas de acordo com a subida e descida das águas, portanto a comunidade se caracteriza como uma das unidades de produção do/a trabalhador/a, e neste compasso, o sujeito organiza o seu calendário de trabalho. "A terra, a floresta e a água participam de modo decisivo da forma como esses agentes sociais procuram dar plenitude à vida" (WITKOSKI, 2010, p. 160). Essa plenitude se relaciona com os processos produtivos que são efetivos num dado espaço, cria-se e recria-se a identidade coletiva entre os indivíduos e o território, é esse o território de trabalho que são desenvolvidas as atividades produtivas. (PEREIRA, et al, 2009).

A organização do calendário de trabalho é constituída a partir da experiência adquirida historicamente; deste modo, o/a trabalhador/a vai produzindo sua existência e seus múltiplos cultivos. Nos pressupostos de Caldart (2004), "o potencial da Agricultura Familiar está na diversidade e nos usos múltiplos dos recursos naturais", tal posicionamento se materializa na comunidade de Nogueira, já que é no chão das terras que são cultivados os diversificados produtos da cadeia alimentar dos trabalhadores e trabalhadoras amazônidas.

Em relação à organização do trabalho na Comunidade, o agricultor e pescador Rio Amazonas ${ }^{15}$ de 26 anos, ao ser entrevistado responde que:

[...] aqui temos tempo para fazer tudo, não dá para perder a época de nada, se quiser comer milho maduro, ele tem que ser plantado no início da vazante. O dia a dia daqui é assim: ora colocamos a

\footnotetext{
${ }^{15}$ Destaca-se que a pesquisa tem autorização do Comitê de Ética e, portanto, os pesquisados assinaram o Termo de Consentimento Livre Esclarecido, que na tentativa de preservar suas identidades utilizaram-se pseudônimos. Entende-se que cada sujeito é concreto, protagonista da sua história e representam todos os Beneditos, Manueis e Marias da imensidão Amazônica.
} 
malhadeira, ora brocamos o roçado e plantamos a mandioca, o milho, e a melancia (Informação verbal) ${ }^{16}$.

O trabalho no campo se relaciona a existência do trabalhador/a. A agricultura e o extrativismo formam o conjunto de saberes, no qual o/a trabalhador/a constrói e reconstrói seus conhecimentos, o "homem, sem dúvida, constitui uma forma de vida, no âmago da natureza" (WITKOSKI, 2014, P.128).

Os ciclos da vida no campo estão articulados aos cotidianos dos trabalhadores/as, já que no processo de desenvolvimento dos modos de produzir, desde a primeira infância, o/a trabalhador/a, vai adequando-se ao percurso da natureza e retira dela, o essencial para a sua existência, fazendo da mesma, uma unidade de produção. Assim, o cotidiano de suas vidas é marcado pela polivalência das atividades. Eles fazem da pesca mais uma de suas atividades, voltadas para o sustento familiar, ao mesmo tempo em que, se reconhecem como pescadores/as, se reconhecem como agricultores/as, pois na condição de posseiros/as, proprietários/as ou arrendatários/as, cultivam espécies, criam animais e caçam. (WITKOSKI, 2014). A este respeito, Witkoski assim se pronuncia:

[...] para quem está fora, o camponês e sua família são vistos, fundamentalmente, como uma fonte de trabalho e de produção de valores de uso, com os quais os grupos ou classes sociais podem aumentar seu fundo de poder. Mas o camponês é, também, e simultaneamente, um agente econômico e o chefe de sua família mais do que isso, sua propriedade é, ao mesmo tempo, uma unidade econômica de produção de valores de uso para si, valores de uso para outras pessoas e seu lar (WITKOSKI, 2010, p. 162).

O trabalho no campo vai além da "subsistência", visto que enquanto categoria fundante o trabalhador/a produz sua existência. Segundo Lessa (2012, p. 28): [...] o trabalho enquanto" categoria fundante é o complexo que cumpre a função social de realizar o intercâmbio material do homem com a natureza". É um conjunto de relações sociais encarregado da reprodução da base material da sociedade eis 0 motivo pela sua natureza ontológica.

No campo pesquisado, a adaptação do trabalhador/a aos ciclos das águas, das terras e das florestas implica na construção de um calendário de trabalho singular, cujas atividades estão estreitamente vinculadas às subidas e descidas dos

\footnotetext{
${ }^{16}$ Informação obtida no período da coleta de dados da pesquisa em 2016.
} 
rios que correspondem ao período de reprodução das espécies de peixes encontradas, bem como das estações do ano, que no lócus em destaque, caracterizam-se como os tempos das cheias e vazantes, do sol e da chuva.

É nessa dialética que o/a trabalhador/a vai construindo a organização do trabalho. A natureza apresenta suas mediações e contradições, de modo que ao ligar as comunidades pelas águas dos rios, furos e igarapés, causa a aproximação de animais peçonhentos e selvagens, como cobras e jacarés à população. "Com relação ao regime de inundação, as várzeas ${ }^{17}$ da Amazônia brasileira formam-se sobre a influência da enchente/cheia/vazante/seca" (WITKOSKI, 2010, p. 116).

Os ciclos das águas representam a materialização "dialética da natureza", já que a descida e subida significa a dinâmica do plantar, cultivar e colher. $O$ trabalho está organizado de acordo com o movimento da natureza, quando termina na terra de várzea, é o período de arregaçar as mangas ${ }^{18} \mathrm{e}$ iniciar as atividades na terra firme, contudo, as atividades produtivas, se articulam e se completam, além de servirem como suporte na elaboração do calendário de trabalho amazônico.

A organização do calendário dos trabalhadores e trabalhadoras segue a influência dos modos e costumes que passaram de geração a geração, pois mediante aos conhecimentos adquiridos ${ }^{19}$ foi articulado e pensado seguindo "as orientações dos instrumentos que a natureza thes oferece, a orientação da natureza no que concerne aos períodos de plantar, cultivar e colher serve como indicativos para as atividades produtivas" (FRAXE et al, 2007, p. 215).

As atividades na terra firme se intensificam no período da enchente, no campo, as dinâmicas do cultivo e da colheita perduram o ano todo, de janeiro a janeiro. Quando a produção da lavoura temporária finda, iniciam as produções da lavoura permanente. As águas disponibilizam no decorrer do ano, os meios de vivência no campo e das florestas o/a trabalhador/a retira o essencial, e das terras brotam as mais diversificadas frutas, que juntamente com a pesca formam a base da alimentação daqueles que ali vivem.

A várzea é um dos principais lócus de trabalho do camponês. No decorrer da vazante as diversas culturas são semeadas, sendo utilizada a fertilização natural do

\footnotetext{
${ }^{17}$ Essas terras são inundadas pelas águas nas épocas de cheias no Amazonas.

${ }^{18}$ É o momento de trabalhar na lavoura. 
solo, cujo resultado, são frutos "vistosos", ou seja, de boa qualidade. Os frutos gerados em terras banhadas pelos rios possuem uma frutificação diferenciada, pois o solo é mais rico devido aos rios Solimões e Tefé (WITKOSKI, 2010).

O Rio Solimões é o rio que banha o território de Alvarães; a comunidade de Nogueira situa-se às margens do Lago de Tefé. As suas águas carregam apreciáveis quantidades de sedimentos, "no fluxo da enchente/cheia e, quando voltam ao seu leito natural, deixam detritos minerais e orgânicos depositados sobre a planície em inundação, dando-Ihe grande fertilidade e valor para a produção intensiva de alimentos" (FRAXE, et al 2007, p. 112).

Na subida e descida das águas ocorre o movimento constante dos modos e costumes dos/as trabalhadores/as. Têm as suas vidas traçadas pelos ciclos da natureza, os quais se apresentam com as suas mediações e contradições, fazendo uma dança. Seguindo o ritmo das águas, homens e mulheres relacionam-se aos diversos trabalhos nas terras/florestas/águas.

O território, local de existência dos sujeitos, está permeado de contradições, de modo que, ora a terra de várzea produz frutas "vistosas", e leva o camponês a indicar a sua preferência por ela, ora se vê diante das alegações, que por questões circunstanciais migram seus processos produtivos para a terra firme. Nessa dinâmica, os trabalhadores/as constroem com o compasso das águas o seu trabalho, seus gestos e formas de vida.

Os trabalhadores e as trabalhadoras não abandonam a terra de várzea em função da terra firme, pois, na verdade, existem dois territórios de trabalho. A várzea localiza-se às margens dos rios e possibilita também, a plantação, o cultivo e a colheita, às vezes no próprio quintal. $\mathrm{O}$ roçado ${ }^{20}$, para muitos se configura a extensão da sua casa e localiza-se na terra de várzea. A terra firme, é uma área que não inunda nas enchentes e o trabalhador utiliza no deslocamento cerca de uma hora ou mais para produzir sua existência, não obstante, tais fatores implicam no fortalecimento da agricultura familiar.

\footnotetext{
${ }^{20}$ É uma área onde os trabalhadores cultivam a terra.
} 


\section{A organização social do trabalho no contexto amazônico}

A organização do trabalho no campo da comunidade de Nogueira é articulada, de acordo, com a diversidade da natureza. A partir dos cultivos de múltiplas produções agrícolas, como é o caso da melancia, do milho e da mandioca, o sujeito produz sua existência. Tais produtos ocupam lugares relevantes nos processos produtivos, contudo a pretensão é evidenciar como se materializa o trabalho com destaque para o plantio da mandioca.

Esses trabalhadores/as têm a ação coletiva da família como motores propulsores do trabalho no campo. Vinculam-se aos recursos naturais que a terra, as florestas e as águas disponibilizam, pois o território caracteriza-se como o local da produção de sua existência, contemplando três habitats essenciais: terra, floresta e água. Em cada um desses habitats existem diversos ecossistemas que "as populações tradicionais se inserem não como dominadoras desse cenário natural, mas como parte integrante consciente dos próprios ecossistemas e usufruem destes apenas para satisfazer suas necessidades" (LIRA, 2012, p. 75).

Os processos que materializam o trabalho no campo da comunidade perpassam por ciclos que não se condicionam em únicos, mas se articulam, de acordo, com as respectivas culturas a serem cultivadas. Por exemplo, a plantação da mandioca, que vai desde a preparação da terra à produção da farinha, conforme apresenta o trabalhador do Rio Uatumã ${ }^{21}$, de 26 anos:

O primeiro passo é a gente procurar um bom local descansado e pôr a roça, aí vem a derrubada da capoeira que às vezes já está grande. Esse trabalho é todo braçal. Aí a gente derruba toda área que vai ser plantada. E depois de derrubada a gente encoivara, encoivara é tacar fogo. Depois que acaba de queimar os paus menores a gente empurra, os maiores ficam lá mesmo, porque são muito grandes e pesados. A limpeza e a coivara, é que temos de fazer primeiro, depois disso, a gente passa para plantar a maniva [… ( (Informação verbal) ${ }^{22}$.

Enquanto sujeito historicamente situados, os trabalhadores e trabalhadoras articulam suas ações no respeito mútuo com a natureza, cuja relevância é a preservação do seu território, já que retira do ambiente o essencial para a sua

\footnotetext{
${ }^{21} \mathrm{~A}$ identidade do sujeito foi preservada conforme orientação do Comitê de Ética.

${ }^{22}$ Informação obtida no período da coleta de dados da pesquisa em 2016.
} 
vivência no campo. Para Silva (2016), o trabalhador/a que retira o essencial para sua existência, não degrada os recursos naturais, pois seus instrumentos são rudimentares, seus costumes são tradicionais, especialmente na organização do trabalho passam de geração a geração, respeitando a terra m parte integrante de existência.

O processo de deixar a terra descansar é um costume, e tem por objetivo reverenciá-la, uma vez que a mesma é fundamental para a sua vivência. Para Fraxe et al (2007, p.114) "quando ocorre o cansaço das terras, em face do seu uso mais intenso, em lugares que não sofrem inundações todos os anos, o camponês tem como costume deixar a terra em descanso - fazer o pousio". Denota que a "capoeira", é na verdade o local onde a terra está passando pela etapa do repouso, para que nos períodos posteriores, esteja propicia as diversificadas formas de cultivo e uso da terra como meio de existência dos trabalhadores e trabalhadoras das comunidades.

Os processos da construção do roçado são necessários os seguintes instrumentos com "o machado, o terçado, o facão" (FRAXE, et al 2009, p.151). Witkoski (2010), afirma que na fabricação de parte dos instrumentos de trabalho, como os cabos de machado ou os remos de canoa, utilizam a paracuúba (Lecointea amazonica - árvore típica da região amazônica). O conjunto dos recursos naturais disponíveis para a vida do trabalhador/a é um elemento estruturante do campo, o que se contrapõe à lógica do agronegócio. Segundo Caldart, Molina e Arroyo (2000), os agricultores familiares são percebidos como portadores de outra concepção de agricultura, diferente e alternativa à agricultura tradicional, à latifundiária e patronal dominante no país.

Os instrumentos de trabalhos, embora rudimentares, são na verdade ,herança dos povos tradicionais que ali estiveram e que, por uma lógica da cultura dominante foram usurpados, tiveram seus nomes esquecidos, mas são relembrados pelos costumes e saberes que atravessaram gerações. "As populações utilizam técnicas baseadas nos recursos naturais, ocorre entre elas uma constante transmissão de conhecimentos através das gerações como forma de perpetuar a identidade do grupo" (FRAXE, et al 2009, p. 94).

$\mathrm{Na}$ realidade o trabalho coletivo é utilizado para suprir em determinados momentos, a força de trabalho familiar. Entre essas práticas está o mutirão ou a 
troca pura e simples de dias de trabalho entre eles. Na verdade esses processos aparecem em função de que os/as trabalhadores/as não dispõem de rendimentos monetários necessários para pagar trabalhadores assalariados. Na comunidade pesquisada esta prática é conhecida como "ajuri", que em articulação com o trabalho coletivo da família, é utilizada para agilizar o trabalho da agricultura familiar camponesa. Segundo Noda (2007, p. 270), "as relações de ajuda mútua, denominadas regionalmente de mutirão, ajuri ou puxirum ${ }^{23}$, apresentam-se como sendo 0 produto das necessidades econômicas dos/as trabalhadores/as amazônidas".

Tais atividades são ações que ocorrem no campo e pelos sujeitos, com sentimentos profundos de pertença a um determinado grupo familiar, ou até mesmo a uma definida classe social, visto que tais atividades ocorrem no espaço onde há resquícios das heranças culturais, e que mesmo estando no modo de produção Capitalista, se consolidam na comunidade de Nogueira.

O ajuri, na comunidade, é realizado em conformidade com a organização do trabalho. A prática do ajuri é conhecida e utilizada pelo/as trabalhadores/as daquele território como um recurso relevante do processo de construção e socialização das suas experiências. "A principal característica é o conhecimento dos processos de trabalho nos subsistemas agrícolas e no extrativismo vegetal e animal, essas relações são tradicionais e caracterizam uma situação na qual há pouca circulação da moeda" (WITKOSKI, 2010, p.173). A mandioca é uma das principais produções da comunidade já que é possível cultivá-la nas terras de várzeas e nas terras. Dentre outros, são seus derivados: a farinha ova, a farinha branca, o beiju, a tapioca, a farinha de tapioca, o pé de moleque e o tucupi.

A mandioca pode ser servida, cozida ou assada. É parte integrante da cadeia alimentar dos animais, já que a "crueira" 24 é jogada para os porcos. Esse processo de trabalho envolve os sujeitos partícipes da lida no campo, que em Nogueira são os homens, as mulheres e as crianças, " na casa de farinha, todos temos as nossas

\footnotetext{
${ }^{23}$ Esses conceitos representam a linguagem regional do contexto pesquisado e significa nesse campo o processo de ajuda mútua entre os trabalhadores (as) sem relação efetiva com a venda da força de trabalho. É um mutirão que é realizado por todos os trabalhadores (as) e ocorre em função de organizar e estabelecer as relações de trabalho; por exemplo, o processo de cultivo da mandioca; é um movimento dinâmico em que todos os comunitários se ajudam mutuamente na tentativa de usufruir integralmente o período propício a plantação para que a colheita seja realizada antes das cheias.
}

${ }^{24}$ Sãos os restos que sobram da macaxeira. 
responsabilidades, os homens torram a massa no forno, as mulheres raspam a mandioca, e as crianças ajudam a carregar água e a jogar as cascas para os porcos" (CADERNO DE PESQUISA DE CAMPO, 2016, p. 1).

Durante as atividades da realização da pesquisa de campo, foi possível observar o espaço de construção de saberes e de fortalecimento das diversas culturas. A produção da agricultura é de relevância para a comunidade, pois além de ser um dos principais meios produtivos, beneficia o fortalecimento das relações sociais entre os comunitários construídos socialmente. A divisão social do trabalho envolve todos da família, visto que é construído socialmente nas relações com os outros indivíduos e principalmente na base familiar. Em Nogueira, cedo a criança é incluída no processo de trabalho, e atividades como raspar a macaxeira, peneirar a massa para fazer a farinha, carregar água para o consumo dos animais são perceptíveis, ali, onde coletivamente constroem conhecimentos que são passados de geração a geração.

O campo revela a força de trabalho dos membros da família, "é impossível renunciar todo e qualquer tipo de trabalho doméstico, porque ele permite adquirir uma série de bons hábitos, que introduzem a civilização no seio da família" (PISTRAK, 2011, p. 25). Assim, o trabalho socialmente construído permite ao sujeito da comunidade articulações distintas com os processos produtivos locais, uma vez que nesse movimento, as relações sociais se entrelaçam e se articulam, e constroem os saberes, os gestos e as diversas formas de labor existente que vão se materializando no trabalho do campo de Nogueira. As responsabilidades que são atribuídas a todos da família, como por exemplo, as irrigações dos cultivos tradicionais permitem a identificação da água como nutriente fundamental para o mantimento da vida das plantas, e deste modo, "[...] o trabalho socialmente útil determina as relações sociais dos seres-humanos" (PISTRAK, 2011, p. 39).

Há uma relação de ajuda mútua, que se articula e se completa "[...] na plantação de milho, enquanto o meu filho do meio fica embalando, o mais novo na rede, que trago para o roçado, eu vou abrindo a cova e o mais velho vai plantando" (CADERNO DE PESQUISA DE CAMPO, 2016, p. 02). Esse argumento potencializa a afirmativa de Pistrak (2011, p. 27) no qual "existem, trabalhos que não exigem conhecimentos especiais, são caracterizados como, limpeza e conservação de jardins, e plantação de árvore" que, no campo da comunidade é formulado pela 
inserção da criança nas relações de trabalho.

Sobre o trabalho na agricultura, Pistrak (2011), afirma que esse trabalho não é estreitamente profissional, mas ligado à vida e à atividade humana em condições puramente naturais. As técnicas e instrumentos utilizados para a manipulação do solo, os modos como os processos produtivos são organizados, caracterizam-se atividades vinculadas à agricultura familiar camponesa. Nas palavras do entrevistado e trabalhador Rio Negro 25 (2016), "quando a gente colhe a mandioca, leva tudo para casa de farinha, lá as mulheres raspam a mandioca, as crianças também ajudam a raspar, ajudam também a carregar água, a jogar as cascas para os porcos".

Há relevância no esclarecimento de que este trabalho precisa ser orientado à criança para que elas participem no trabalho social de forma ativa, consciente e socialmente explicada. A orientação a ser direcionada está embutida de intencionalidades e possui estreita ligação ao projeto da classe trabalhadora que, segundo Caldart, Molina e Arroyo (2000) é histórico e tem a ver com as diversas realidades particulares, que por sua vez guardam relação com a realidade socialmente construída.

A sinalização evidencia a intencionalidade da concepção da Educação do/no campo na comunidade de Nogueira, enquanto ação que compreende a educação como um direito e reconhece a enorme dívida do poder público em relação ao direito dos povos do campo à educação (BRASIL, 2013).

Para Caldart, Molina e Arroyo (2000), um projeto de classe tem como pressuposto a compreensão do processo histórico e do tipo de sociedade que se quer construir. Isso requer uma análise crítica da sociedade, estabelecendo um movimento o universal e singular. Para os autores, as práticas de transformação ocorrem em cada assentamento, fato este que, no contexto amazônico, acontece em cada calha dos rios e igarapés que banham as comunidades camponesas, nos processos de trabalho em que homens e mulheres retiram das terras, das florestas e das águas o necessário para sua existência.

A Educação do Campo nasce colada aos processos produtivos do campo, significa dizer que a valorização do trabalho que forma e produz o ser humano é necessário, uma vez que possibilita a dignidade para as famílias das comunidades.

\footnotetext{
${ }^{25} \mathrm{~A}$ identidade do sujeito foi preservada conforme orientação do Comitê de Ética.
} 
Caldart, Molina e Arroyo (2000), afirmam que o trabalho produz cultura, produz também a classe trabalhadora que se organiza e luta pela superação das condições de alienação que historicamente os caracterizaram como sujeitos excluídos a todo e quaisquer formas de direitos.

\section{Considerações finais}

O campo da pesquisa que se desdobrou na escrita é o campo da agricultura familiar camponesa e de trabalhadores/as amazônidas, representado pela singularidade da comunidade de Nogueira. O Trabalho é considerado a categoria fundante da existência do ser social, a sua análise nesta pesquisa se fez a partir do Materialismo Histórico Dialético, que estuda os modos de produção e, com eles, os processos produtivos que caracterizam a vida na sociedade.

Ao retratar a centralidade do trabalho na formação humana, ressalta-se que nas comunidades primitivas, caracterizadas pelos modos de vidas baseados nas coletas de frutos e caças de animais, o trabalho se consistia na produção de conhecimentos e na socialização dos saberes que passavam de geração a geração. No entanto, à medida que as sociedades se desenvolveram, o trabalho se metamorfoseou, cujo principal fim passou a ser a exploração do trabalhador que, sob o comando de outro ser humano, perde o controle do que produz.

Os campos das águas, das terras e das florestas apresentam formas de organização do trabalho, historicamente constituídos. As terras firmes e de várzeas são os lócus dos processos produtivos. O calendário de trabalho é organizado, de acordo com as cheias e as secas. A agricultura familiar camponesa é atividade de maior predominância, e é desenvolvida por meio das lavouras permanentes e temporárias, nas quais a mandioca, a melancia e a banana exercem maior representatividade entre os produtos cultivados. A divisão do trabalho revela a força de trabalho do homem, da mulher e da criança; deste modo, se organizam e se articulam mutuamente.

As categorias analisadas permitiram a compreensão de como o trabalho nas águas, nas terras e nas florestas é organizado. Assim, o texto aponta a adaptação do/da trabalhador/a aos ciclos das águas, das terras e das florestas que implica na construção de um calendário de trabalho, cuja dinâmica respeita o período das 
reproduções das espécies, bem como as estações do ano. O transporte das lavouras é realizado nas chalanas ou canoas motorizadas, sendo que a maioria dos/as trabalhadores/as pagam os barcos de propriedade privada para a realização do transporte ou vendem para o atravessador, havendo um movimento de agregação de valor aos produtos.

As análises evidenciam que o trabalhador/a produz, no entanto, as políticas públicas são insuficientes. O trabalho na comunidade de Nogueira é realizado nas terras/florestas/águas e tem estreita relação com cada componente familiar, tanto que é perceptível a relação social construída a partir da sua organização coletiva. O palco do território amazônico é o de quem vive das águas, das terras e das florestas.

\section{Referências}

BORGES, H. da S. Formação continua de professores (as) da Educação do Campo no Amazonas. 2015. 206 f. Tese (Doutorado em Educação) - Universidade Federal do Amazonas, Faculdade de Educação, 2015.

BRASIL. Ministério da Educação. Portaria no 87 de 01 de fevereiro de 2013. Brasília: Distrito Federal, 2013.

CALDART, R. S. C.; KOLLING, E. J. Educação do campo: identidade e políticas públicas. Articulação Por Uma Educação do Campo: Brasília, DF, 2002.

CALDART, R.S. Elementos para a construção do Projeto Político Pedagógico da Educação do Campo In: Por uma educação do campo: contribuições para a Construção de um projeto de Educação do Campo. (Coleção Por Uma Educação do Campo, 5). Brasília, Distrito Federal (2004).

CALDART, R.S; MOLINA, M. C.; Arroyo, M.G. Contribuições para a construção de um projeto de Educação do Campo. (Coleção Por Uma Educação Básica do Campo). Brasília, Distrito Federal, 2000.

FRAXE, T. de J; WITKOSKI, A. C.; PEREIRA, H. Comunidades ribeirinhas amazônicas: modos de vida e uso dos recursos naturais. Manaus: EDUA, 2007.

FRAXE, T.de J; WITKOSKI, A. Carlos; SILVA, C. P. A pesca na Amazônia central: ecologia, conhecimento tradicional e formas de manejo. Manaus: Editora Universidade Federal do Amazonas, 2009.

LESSA, S. Mundo dos homens: trabalho e ser social. São Paulo: Instituto Lukács, 2012.

LIRA, S. H. Sustentabilidade e territorialidade humana: desafios, tendências e possibilidades para as populações rurais amazônicas.2012. Disponível em: 
https://docplayer.com.br/85530978-Sustentabilidade-e-territorialidade-humanadesafios-tendencias-e-possibilidades-para-as-populacoes-rurais-amazonicas.html. Acesso em: 21 de jan. 2017.

MARX, K. Para a crítica da economia política. Tradução Edgard Maladodi. São Paulo: abril Cultural, 1982.

MARX, Karl Heinrich. Grundrisses. São Paulo: Boitempo, 2011. 1285 p. Tradução de Mario Duayer; Nélio Schneider. E books da Boitempo Editorial.

MOLINA, M. C. A contribuição do Pronera na construção de políticas públicas de educação do campo e desenvolvimento sustentável. 2003. Tese. (Doutorado em Desenvolvimento Sustentável) - Centro de Desenvolvimento Sustentável da Universidade de Brasília, Brasília, 2003.

MOURÃO, A. R. B. Educação no campo: uma realidade construída historicamente. São Paulo: Cortez, 2012.

NODA, S. do N. Agricultura familiar na Amazônia das águas. Manaus: Editora da Universidade Federal do Amazonas, 2007.

OLIVEIRA, A. U de. Modo de produção capitalista, agricultura e reforma agrária. São Paulo: FFLCH, 2007.

PEREIRA, C. F; SILVA, S. C. P. da; WITKOSKI, A. C; CRUZ, M. de J. M. da; FRAXE, T. de J. P. (org.). Territorialidades específicas e formas de apropriação dos territórios aquáticos no baixo Solimões. In: FRAXE, Therezinha de Jesus Pinto; WITKOSKI, Antônio Carlos; SILVA, Suzy Cristina Pedrosa da (org.). A pesca na Amazônia Central: ecologia, conhecimento tradicional e formas de manejo. Manaus: Editora da Universidade Federal do Amazonas, 2009.

PISTRAK, M. M. Fundamentos da escola e do trabalho. São Paulo: Expressão Popular, 2011.

SILVA, C. A. Área de interface ceramista pretérita: a coleção arqueológica José Alberto Neves. 2016.2010f. Tese (Doutorado em Sociedade e Cultura) Universidade Federal do Amazonas, Manaus, 2016.

SILVA, O. B. As representações sociais de trabalho e educação em comunidades ribeirinhas. 2010.194.f. Dissertação (Mestrado em Educação) Universidade Federal do Amazonas, Manaus, 2010.

UCHÔA, I. C. Caderno de pesquisa de campo, nas localidades do Médio rio Solimões. (Inédito), 2016.

UCHOA, I. C; MOURÃO, A. R. B. De Parauari a Nogueira: o resgate de uma história no coração do Amazonas. Revista: Caribeña de Ciencias Sociales, Málaga, Espanha, v. 10, n. 10, p. 1-12, 22 out. 2019. Mensal. Disponível em: https://www.eumed.net/rev/caribe/2019/10/historia-coracao-amazonas.html.

Acesso em: 09 jun. 2020. 
WAGLEY, C. Uma comunidade Amazônica. Belo Horizonte MG: Itatiaia, 1988.

WITKOSKI, A. C. Terras, florestas e águas de trabalho: os camponeses amazônicos e as formas de uso de seus recursos naturais. São Paulo: Annablume, 2010.

WITKOSKI, A. C.; FRAXE, T. de J.; CAVALCANTE, K. V. Território e territorialidade na Amazônia: formas de Sociabilidade e participação Política. Manaus: Editora Vale, 2014. 